\section{Contributors}

Anton B Alexandroff has been recently appointed as a new consultant dermatologist in Leicester Royal Infirmary. His special interests are psoriasis (including its systemic manifestations such as atherosclerosis) and skin cancers. anton.alexandroff@gmail.com

Oliver Boylan delivers courses in medical and dental education for NIMDTA and Queen's University, Belfast.

\section{Dr Fergus Donaghy}

GP Trainer \& Programme Director at NIMDTA and Honorary Clinical Lecturer at Queen's University, Belfast.

fergusdonaghy@msn.com

\section{Edzard Ernst}

Edzard.Ernst@pms.ac.uk

\section{Mike Fitzpatrick}

fitz@easynet.co.uk

\section{Emyr Gravel}

emyrwyn@doctors.org.uk

Steve lliffe, is a Professor of Primary Care for Older People, University College London.

s.iliffe@pcps.ucl.ac.uk

Graham Johnston is a consultant dermatologist in Leicester. His special interests are eczema and psoriasis. graham.johnston@uhl-tr.nhs.uk

Professor Cindy Lam works at the Family Medicine Unit, University of Hong Kong.

\section{Dr Claire M Loughrey}

Director of GP Post Graduate Education at NIMDTA.

\section{Andrew Papanikitas is a $\mathrm{PhD}$}

candidate at the Centre for Biomedicine and Society looking at ethical decisionmaking strategies which are used by UK GPs. He is a newly-qualified GP, teaches consultation skills to medical students and organises postgraduate meetings at The Royal Society of Medicine. He has co-written two books, Get Through Clinical Finals and Get through DCH Clinical for the RSM Press. He is currently organising a multidisciplinary half-day examining multiple aspects of the Doctrine of Double Effect in end-oflife settings which takes place at the RSM on 1 February 2010. andrew.papanikitas@kcl.ac.uk

\section{Joe Rosenthal works at the} Department of Primary Care \& Population Health, UCL Medical School. j.rosenthal@pcps.ucl.ac.uk

Ann Stephenson works at the Department of General Practice and Primary Care, King's College London. anne.stephenson@kcl.ac.uk

Dr Joyce T'ang is a Director at the United Christian Nethersole Community Health Service, Hong Kong.

Professor Jean Woo is a Professor of Medicine, Chinese University of Hong Kong.

\title{
America's tortured brow
}

I'm startled to see a message on my surgery computer screen telling me Mickey Mouse is dead. Along with Minnie and $\mathrm{Mr}$ and Mrs Test and a few others, he has served us well as a dummy patient but obviously the years of ill health we have callously enforced on him have taken their toll and he has moved on to that great animation board in the sky.

The untimely death of a much-loved celebrity destined to live out his latter years in a perpetual childlike state in a theme park has unfortunate familiar echoes. I hope the news doesn't get out to his fellow Americans too soon. Many of them already seem to have a poor opinion of the NHS from their responses to Barack Obama's proposed health reforms. It looks like his proposals are now successfully going through Congress despite what has been at times furious resistance from his political opponents. The anti-reform lobby has made much of what they claim is the dire state of health care in Britain. TV adverts and public meetings have painted a bleak picture of patients routinely being allowed to die from lack of the most basic treatment. Other outlandish claims were that people like Stephen Hawkins would not get treatment on the NHS and Edward Kennedy would have been left to die.

Unfortunately some of these opinions have been reinforced by selective quotes from some British healthcare experts like the cancer Tsar Karol Sikora. Of course those of us working in the NHS would have to be completely deluded if we weren't aware of the serious deficiencies and problems which are a day-to-day part of the struggle of trying to look after our patients. The NHS desperately needs reform as well as more funding. But not just any reform.

The mantra of this government is more choice. Among the bright ideas for modernising are more immediate access through walk-in centres, instant protocolderived advice from NHS Direct, using new polyclinics as a one stop shop, being able to register with more than one GP, and abolishing surgery boundaries. Essentially allowing patients to shop around and sidelining traditional general practice and continuing care from a personal GP.

In fact, we GPs seem to be increasingly viewed as barriers to patients getting appropriate and timely care rather than their advocate. The lack of health care for 20 million uninsured Americans is a scandal but the death of Michael Jackson and his reported medical treatment shines an unexpected light on the dark side of having too much money and choice. Home propofol injections aren't common treatment in the rickety NHS. Privilege doesn't always bring the best care. I was astonished at the number of prescription drugs the actor Heath Ledger was taking when he died. I can't think of many 28 year olds who would be prescribed several different opioids, benzodiazepines, hypnotics, and antihistamines for pain, stress, and anxiety over here.

US News magazine commenting on his death claimed that 20000 Americans a year died from mix-ups over drugs often prescribed from several different doctors. They went on to quote Edward Langston, chair of the board of trustees for the American Medical Association on how to avoid the same fate. 'It's a good idea for anyone who needs several medications to have a primary care physician, who can keep track of all of their care, it's not unusual for people to get prescriptions from different doctors and fail to share a list of all of the drugs they're taking prescription and over the counter with each physician. That person can be on guard against the danger of cumulative effects.

A primary care physician taking overall responsibility, now there's a novel idea the NHS could take up, but unfortunately too late to save poor Mickey.

\section{REFERENCE}

1. Payne JW. Prescription drugs: how to avoid Heath Ledger's fate. US News, February 8, 2008. http://www usnews.com/health/articles/2008/02/0 8/prescription-drugs-how-to-avoid-heathledgers-fate.html (accessed 18 Jan 2010).

DOI: 10.3399/bjgp10X483418 